\title{
ANATOMIA DO LENHO DE CALYPTRANTHES TRICONA D. LEGRAND (MYRTACEAE) ${ }^{1}$
}

\section{SIDINEI RODRIGUES DOS SANTOS ${ }^{2}$ JOSE NEWTON CARDOSO MARCHIORI ${ }^{3}$}

\section{RESUMO}

Foram estudados os caracteres anatômicos do lenho de Calyptranthes tricona D. Legrand, a partir de material proveniente do Rio Grande do Sul. Salientam-se, para a identificação da espécie: o arranjo do parênquima axial; a ausência de cristais e de conteúdos; a freqüência de poros $\left(<20 / \mathrm{mm}^{2}\right)$ e de raios $(30 / \mathrm{mm})$; e a altura das séries de parênquima axial (2-8 células).

Palavras-chave: Calyptranthes tricona, anatomia da madeira, Myrtaceae.

\section{ABSTRACT}

[Wood anatomy of Calyptranthes tricona D. Legrand (Myrtaceae)].

The wood anatomical features of Calyptranthes tricona D. Legrand were studied, based on specimens from Rio Grande do Sul state, Brazil. To the species' recognition showed special importance: the axial parenchyma arrangement; the absence of crystals and organic inclusions; the frequency of pores $\left(<20 / \mathrm{mm}^{2}\right)$ and rays $(30 /$ $\mathrm{mm}$ ); and the height of axial parenchyma strands (2-8 cells).

Key words: Calyptranthes tricona, wood anatomy, Myrtaceae.

\section{INTRODUÇÃO}

Calyptranthes tricona é árvore nativa de até $15 \mathrm{~m}$ de altura, de casca lisa, exfoliante e cor cinzenta, por vezes com máculas castanhas. Conhecida, popularmente, como guaburiti ou jabuticaba-braba, a espécie ocorre naturalmente na Argentina e Brasil, do Paraná ao Rio Grande do Sul. Neste Estado, distribui-se na Floresta Estacional do Alto Uruguai e, eventualmente, na Encosta Inferior do Nordeste. Calyptranthes tricona é facilmente reconhecida pelas inflorescências trifloras, de flores sésseis concentradas no ápice e, sobretudo, pela abundante presença de tricomas, tanto nas flores, como nos ramos novos e face abaxial das

1 Recebido para publicação em 10/10/2009 e aceito para publicação em 20/01/2010.

2 Biólogo, bolsista do $\mathrm{CNPq}$ - Brasil, doutorando do Programa de Pós-Graduação em Engenharia Florestal, Departamento de Ciências Florestais, Universidade Federal de Santa Maria. CEP 97105-900. Santa Maria, RS, Brasil. sthurt.bio@gmail.com

3 Engenheiro Florestal, Dr., bolsista de Produtividade em Pesquisa do CNPq, Professor Titular do Departamento de Ciências Florestais, Universidade Federal de Santa Maria, Santa Maria, RS, Brasil. balduinia@mail.ufsm.br folhas (Marchiori \& Sobral, 1997; Sobral, 2003).

No Rio Grande do Sul, o gênero Calyptranthes conta com outras 6 espécies (Mattos, 1983), utilizadas quase exclusivamente como lenha (Legrand \& Klein, 1971). Com exceção de Calyptranthes concinna DC., estudada por Marchiori \& Brum (1997), as demais carecem de estudo anatômico detalhado de suas madeiras. O presente estudo visa a preencher esta lacuna, contribuindo para o melhor conhecimento estrutural das Mirtáceas nativas no Rio Grande do Sul.

\section{REVISÃO DE LITERATURA}

Com relação à anatomia, são muito escassas as referências sobre as madeiras brasileiras de Calyptranthes, notadamente das espécies nativas no Rio Grande do Sul.

Em estudo de Calyptranthes concinna, Marchiori \& Brum (1997) relacionam: porosidade difusa; poros solitários $\left(11 / \mathrm{mm}^{2}\right)$; placas de perfuração simples $(510 \mu \mathrm{m})$; pontoações raio-vasculares e parênquimo-vasculares ornamentadas; parênquima apotraqueal em séries de $4-8$ células; raios heterogêneos (24/ 
$\mathrm{mm}$ ), com $1-3$ células de largura e abundantes conteúdos; e presença de fibrotraqueídeos (999 $\mu \mathrm{m})$. É mencionada, também, a ausência de cristais, de espessamentos espiralados e de traqueídeos.

Para Calyptranthes langsdorffii, Barros et al. (2001) referem, entre outros aspectos: porosidade difusa; poros exclusivamente solitários $\left(5 / \mathrm{mm}^{2}\right)$, com conteúdo marrom; placas de perfuração simples $(667 \mu \mathrm{m})$; parênquima apotraqueal difuso-em-agregados, em linhas tangenciais e em séries de 4 a 11 células; raios heterogêneos $(18 / \mathrm{mm})$, com $1-3$ células de largura; e presença de fibrotraqueídeos (1284 $\mu \mathrm{m})$. Merecem destaque, ainda, a ocorrência de traqueídeos e de cristais no parênquima axial.

Para o gênero, Metcalfe \& Chalk (1972) citam: vasos pequenos, solitários e em ocasionais múltiplos de $2-3$, por vezes com frequiência de $40-100 / \mathrm{mm}^{2}$; raios de $4-6$ células de largura, com 1 - 3 fileiras marginais de células eretas, por vezes com freqüência inferior a $13 / \mathrm{mm}$; e parênquima paratraqueal aliforme até confluente, em algumas espécies.

\section{MATERIAL E MÉTODOS}

O material em estudo consiste de uma amostra de madeira, coletada na mata ciliar do rio das Antas, no município de Nova Roma do Sul, Rio Grande do Sul. A amostra de madeira e respectiva exsicata botânica foram incorporadas à Xiloteca e Herbário do Departamento de Ciências Florestais (HDCF) da Universidade Federal de Santa Maria, com o número 6089.

Do material lenhoso foram extraídos três corpos de prova $(3 \times 3 \times 3 \mathrm{~cm})$ da parte mais externa do lenho, próxima ao câmbio, orientados para obtenção de cortes nos planos transversal, longitudinal radial e longitudinal tangencial. Um outro bloquinho foi também retirado, com vistas à maceração.

Os corpos de prova foram amolecidos por fervura em água e seccionados em micrótomo de deslizamento, regulado para a obtenção de cortes anatômicos com espessura nominal de
$20 \mu \mathrm{m}$. Os cortes foram tingidos com acridinavermelha, crisoidina e azul-de-astra (Dujardin, 1964), desidratados em série alcoólica-ascendente $(30 \%, 50 \%, 70 \%, 95 \%$ e duas vezes em álcool absoluto), diafanizados em xilol e montados em lâminas permanentes, usando-se Entellan como meio de montagem.

Para as lâminas de macerado, adotou-se o método de Franklin, modificado (Kraus \& Arduin, 1997), coloração da pasta com safranina $1 \%$ e montagem em lâminas permanentes, com Entellan.

A descrição microscópica da madeira baseou-se nas recomendações do IAWA Committee (1989). No caso da percentagem dos tecidos, foram realizadas 600 determinações ao acaso, com auxílio de contador de laboratório, conforme proposto por Marchiori (1980). A freqüência de poros foi obtida de forma indireta, a partir de um quadrado de área conhecida superposto a fotomicrografias de seção transversal da madeira. As medições foram realizadas em microscópio Carl Zeiss, com ocular de escala graduada, no Laboratório de Anatomia da Madeira da Universidade Federal de Santa Maria. Nas características quantitativas, os números entre parênteses equivalem aos valores mínimos e máximos observados. O valor que acompanha a média é o desvio padrão. As fotomicrografias foram tomadas em microscópio Olympus cx40, equipado com câmera digital Olympus Camedia c3000.

\section{DESCRIÇÃO ANATÔMICA}

Anéis de crescimento: distintos, delimitados por fina camada de fibras radialmente estreitas no lenho tardio (Figura 1A,B).

Vasos: pouco numerosos a numerosos $(17 \pm$ $5\left(12-25\right.$ poros $\left./ \mathrm{mm}^{2}\right)$, ocupando $7 \pm 2 \%$ do volume da madeira. Conteúdo de coloração escura, muito escasso. Porosidade difusa. Vasos exclusivamente solitários, de seção circular a oval, pequenos $(70 \pm 17(37,5-105) \mu \mathrm{m})$, de paredes espessas $(4,2 \pm 0,8(2,5-6,2) \mu \mathrm{m}) \mathrm{e}$ sem padrão definido de organização (Figura 
1A,B). Elementos vasculares de comprimento médio $(487 \pm 117,6(320-790) \mu \mathrm{m})$, com placas de perfuração simples, oblíquas a transversais, e apêndices geralmente em ambas as extremidades. Espessamentos espiralados, ausentes. Pontoações intervasculares alternas, circulares $(5,8 \pm 0,4(5,1-6,1) \mu \mathrm{m})$, com abertura em fenda inclusa, ornamentada (Figura 1D). Pontoações raio-vasculares com bordas distintas, semelhantes às intervasculares, embora menores $(3,3 \pm 0,3(3,1-3,6) \mu \mathrm{m})$ e restritas ou não às células marginais de raios.

Parênquima axial: muito distinto das fibras, ocupando $16 \pm 3,6 \%$ do volume da madeira; apotraqueal difuso, difuso-em-agregados e em curtos segmentos tangencias com $1-4$ células de largura, por vezes unilaterais, menos comumente paratraqueal escasso (Figura 1A,B). Séries parenquimáticas de $431 \pm 99,9(260-610)$ $\mu \mathrm{m}$ de altura e (2) $4-8$ células (Figura 1F).

Raios: muito numerosos (30 $\pm 4(25-36$ raios $/ \mathrm{mm}$ ), ocupando $19,5 \pm 3,3 \%$ do volume da madeira. Raios heterocelulares com células procumbentes, na parte multisseriada, e 1-11, mais comumente $2-4$ fileiras marginais de células eretas ou quase exclusivamente eretas (Figura 1C). Raios estreitos, com $1-3$ células de largura, predominantemente unisseriados (Figura 1E,F). Os multisseriados, de $406 \pm 162$ (150 -840) $\mu \mathrm{m}$ de altura e $8-23$, mais comumente 10 - 17 células; com parte multisseriada geralmente mais curta do que as margens unisseriadas. Os unisseriados, de 239,2 $\pm 151,7$ $(60-630) \mu \mathrm{m}$ de altura e $1-12$, mais freqüentemente $2-6$ células. Raios axialmente fusionados, escassos. Células radiais de paredes disjuntas, presentes. Raios agregados, inclusões minerais, células envolventes e células perfuradas, ausentes.

Fibras: com pontoações distintamente areoladas, nas faces radiais e tangenciais da parede, representando $57,3 \pm 5,3 \%$ do volume da madeira; de comprimento médio (1064 \pm $106,8(860$ - 1270) $\mu \mathrm{m})$, com $15,8 \pm 1,9(13,7-$ 20) $\mu \mathrm{m}$ de largura e paredes finas a espessas
$(4,2 \pm 0,6(3,1-5,6) \mu \mathrm{m})$ (Figura 1B). Fibras septadas, fibras gelatinosas e espessamentos espiralados, ausentes. Traqueídeos vasicêntricos, presentes.

Outros caracteres: variantes cambiais, tubos laticíferos e taniníferos, canais intercelulares, máculas, células oleíferas ou mucilaginosas, estratificação e cristais, ausentes.

\section{ANÁLISE DA ESTRUTURA ANATÔMICA}

A estrutura anatômica de Calyptranthes tricona reúne características típicas para o conjunto das Myrtaceae, segundo autores como Record \& Hess (1949), Metcalfe \& Chalk (1972) e Vliet \& Baas (1984). É o caso da porosidade difusa, dos poros solitários, dos elementos vasculares de comprimento médio, das placas de perfuração simples, das pontoações intervasculares alternas e ornamentadas, do parênquima predominantemente apotraqueal e seriado, dos raios heterogêneos e estreitos, das fibras de comprimento médio, com pontoações areoladas, e dos traqueídeos vasicêntricos.

A respeito das referências de Metcalfe \& Chalk (1972) para o gênero, cabe salientar diferenças no tocante à freqüência de poros, bem como na largura e freqüência de raios. Na espécie em estudo, os poros são menos numerosos e os raios mais estreitos e frequentes. Sobre este último aspecto, cabe frizar a sua importância na a identificação de Mirtáceas nativas, pois em poucas espécies observam-se valores inferiores a $30 / \mathrm{mm}^{2}$, destacando-se, entre outras: Calyptranthes concinna, Eugenia involucrata e Campomanesia xanthocarpa.

Com relação ao referido por Barros et al. (2001) para Calyptranthes langsdorffii, as diferenças mais importantes dizem respeito à freqüência de poros e de raios, bem como à altura das séries de parênquima; no material em estudo, os valores observados ficaram acima e abaixo, respectivamente, dos fornecidos pelos referidos autores. Eles também referem a presença de cristais no parênquima axial, caráter não observado na espécie em estudo, bem como em 

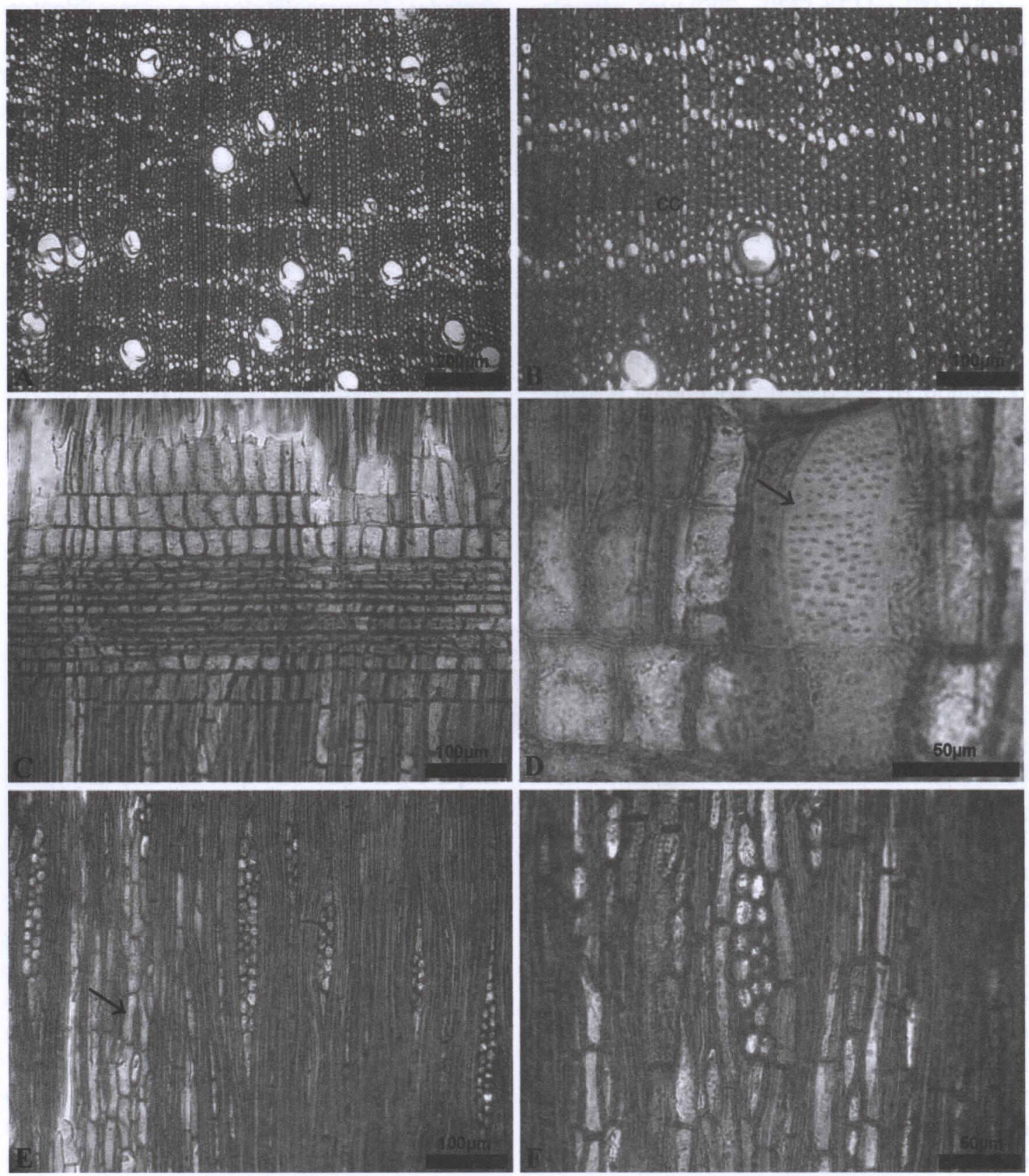

FIGURA 1 - Fotomicrografias da madeira de Calyptranthes tricona. A - Seção transversal, mostrando porosidade difusa, poros exclusivamente solitários e parênquima apotraqueal difuso, difuso-em-agregados e em curtos segmentos tangenciais (seta). B - Mesma seção, em maior aumento, com destaque para o limite de anel de crescimento (cc), fibras de paredes finas a espessas e arranjo do parênquima axial. C - Aspecto geral de raio heterogêneo, com células procumbentes, no corpo central, e margens de células quase exclusivamente eretas (seção longitudinal radial). D - Detalhe da seção radial, mostrando vaso com pontoações intervasculares alternas (seta). E-Raios com 1-3 células de largura e série de parênquima axial (seta), em seção longitudinal tangencial. F - Mesmos aspectos e plano anatômico da foto anterior, com maior aumento. 
Calyptranthes concinna, investigada por Marchiori \& Brum (1997).

Muito semelhantes entre si, Calyptranthes tricona e Calyptranthes concinna diferem, principalmente, pelo arranjo do parênquima axial. Na última destas espécies, não se observa o padrão em curtos segmentos tangenciais. Este caráter, aliás, é tido como importante, sob o ponto de vista taxonômico, por sua ocorrência mais restrita na família (Wiedenbrug, 1948; Vliet \& Baas, 1984; Dias-Leme et al., 1995; Soffiatti \& Angyalossy-Alfonso, 1999). Outro aspecto de eventual utilidade para a separação das espécies é a presença de conteúdos em raios: Calyptranthes concinna apresenta abundante conteúdo, ao contrário de Calyptranthes tricona.

Das características qualitativas, revestem-se de importância para a identificação da espécie em estudo, $o$ arranjo do parênquima axial, bem como a ausência de cristais e de conteúdos na madeira. Dos aspectos quantitativos, salientamse a freqüência de poros e raios, bem como a altura das séries de parênquima axial.

\section{REFERÊNCIAS BIBLIOGRÁFICAS}

BARROS, C.F.; CALLADO, C.H.; MARCON, M.L.; COSTA, C.G.; CUNHA, M.; LIMA, H.R.P.; MARQUETE, O. Madeiras da Mata Atlântica: anatomia do lenho de espécies ocorrentes nos remanescentes florestais do estado do Rio de Janeiro, Brasil. Rio de Janeiro: Instituto de Pesquisas Jardim Botânico do Rio de Janeiro, 2001. $94 \mathrm{p}$.

DIAS-LEME, C.L.; GASSON, P.; LUGHADA, E.N. Wood anatomy of four Myrtaceae genera in the subtribe Myrciinae from South America. IAWA Bulletin, v. 16, p. 87-95, 1995.

DUJARDIN, E.P. Eine neue HolzZellulosenfaerbung. Mikrokosmos, n. 53, p. 94, 1964.

IAWA COMMITTEE. IAWA list of microscopic features for hardwood identification. IAWA Bulletin., v. 10, n. 3, p. 218-359, 1989.
KRAUS, J.E.; ARDUIN, M. Manual básico de métodos em Morfologia Vegetal. Rio de Janeiro: EDUR, 1997. 198 p.

LEGRAND, D.; KLEIN, R.M. Mirtáceas. 6. Calyptranthes Sw. In: REITZ, P.R. Flora Ilustrada Catarinense. Itajaí, Santa Catarina, 1971. p. 494-552.

MARCHIORI, J.N.C. Estudo anatômico do xilema secundário de algumas espécies dos gêneros Acacia e Mimosa, nativas no Estado do Rio Grande do Sul. 1980. 186f. Dissertação (Mestrado em Engenharia Florestal) - Universidade Federal do Paraná, Curitiba, 1980.

MARCHIORI, J.N.C.; BRUM, E.T. Anatomia da madeira do guamirim-facho, Calyptranthes concinna DC. (Myrtaceae). Ciência Rural, Santa Maria, v. 27, n. 2, p. 217-222, 1997.

MARCHIORI, J.N.C., SOBRAL, M. Dendrologia das Angiospermas: Myrtales. Santa Maria: Editora UFSM, 1997. 304 p.

MATTOS, J. R. Mirtaceae do Rio Grande do Sul. Roessléria, Porto Alegre, v. 5, n. 2, p. 171-359, 1983.

METCALFE, C.R.; CHALK, L. Anatomy of the Dicotyledons. Oxford: Clarendon Press, 1972. $1500 \mathrm{p}$.

RECORD, S.J.; HESS R.W. Timbers of the New World. New Haven: Yale University Press, 1949. $640 \mathrm{p}$.

SOBRAL, M. A família Myrtaceae no Rio Grande do Sul. São Leopoldo: Editora Unisinos, 2003. $216 \mathrm{p}$.

SOFFIATTI, P.; ALFONSO, V.A. Estudo anatômico comparativo do lenho e da casca de duas espécies de Eugenia L. (Myrtaceae). Revista Brasileira de Botânica, São Paulo, v. 22, n. 2, p. 175184, 1999.

VLIET, G.J.C. van; BAAS, P. Wood anatomy and classification of the Myrtales. Annals of the Missouri Botanical Garden, n. 71, p. 783-800, 1984.

WIEDENBRUG, W. Maderas chilenas: contribución a su anatomía e identificación. Lilloa, Tucuman, n. 16, p. 263-375, 1948. 